\title{
Adaptation and Testing of Interpersonal Psychotherapy for Military Spouses
}

\author{
Helen Verdeli (Corresponding Author) \\ Department of Counseling and Clinical Psychology \\ Teachers College, Columbia University \\ 525 West $120^{\text {th }}$ Street, Box 102, New York, 10027, USA
}

Tel: 1-212-543-5262 E-mail: hv2009@columbia.edu

\author{
Eleni Vousoura \\ Department of Counseling and Clinical Psychology \\ Teachers College, Columbia University \\ 525 West $120^{\text {th }}$ Street, Box 102, New York, 10027, USA
}

Charles Baily

Teachers College, Columbia University, USA

Alexander Belser

Teachers College, Columbia University, USA

Erica Van De Wal

Teachers College, Columbia University, USA

Gail Manos

Navy Medical Center Portsmouth, USA

Received: September 24, 2011

Accepted: October 24, 2011

Published: December 30, 2011

doi:10.5539/jedp.v1n1p118

URL: http://dx.doi.org/10.5539/jedp.v1n1p118

This study was supported by the Navy Bureau of Medicine and Surgery (BUMED) grant (CIP\# NMCP.2010.00) (CAPT. Gail Manos, PI; Helen Verdeli, Partner PI). Helen Verdeli is supported by National Institutes of Mental Health K23 Award (MH071530).

\begin{abstract}
The psychological impact of current military operations on service members deployed to Iraq and Afghanistan is well established. A number of recent studies have also demonstrated high rates of mental health difficulties, especially depression and anxiety, in spouses of deployed service members. This paper describes the adaptation of interpersonal psychotherapy (IPT), an evidence-based treatment for depression, to target depression in military spouses. The principles of IPT are outlined, and the ways in which the structure and content of the treatment lend themselves to the military context are described. Finally, a study currently underway to adapt and evaluate the treatment is presented and aspects of the treatment are illustrated.
\end{abstract}

Keywords: Military spouses, Depression, Interpersonal Psychotherapy, Treatment adaptation 


\section{Introduction}

The psychological toll of current military operations on service members deployed to Iraq and Afghanistan is well established (American Psychological Association Presidential Task Force, 2007). Recent research suggests that these operations are also placing considerable strain on the mental health of military families. A great number of families in the U.S. are affected by the mental health impact of the war: more than half of the 3.6 million military personnel are married, and of these over 75\% have dependent children (Deputy Under Secretary of Defense, 2009; National Military Family Association, 2004).

Compared to the routine deployments of the prior 20 years, the operational conditions in Iraq and Afghanistan have increased the stress on military families (for a recent review, see Verdeli et al., 2011). High operational tempo (OPTEMPO), multiple and dangerous deployments, historically long periods of separation, and shortened dwell times at home take a substantial toll on service members' spouses and children (Sheppard, Malatras, \& Israel, 2010).

It was initially suggested that the majority of families adapted successfully to the challenges presented by current deployments and continued to function well (Cozza, Chun, \& Polo, 2005; Wiens \& Boss, 2006). However, recent studies (Eaton et al., 2008; Gorman, Blow, Ames, \& Reed, 2011; Mansfield et al., 2010) have reported elevated rates of psychopathology, especially depression and anxiety, in service members' spouses compared to community norms (Kessler et al., 1994, 2003). Whereas rates of anxiety have been shown to drop significantly following the service member's return, depression in military spouses appears to persist following deployment (Lester et al., 2010).

A number of psychosocial programs addressing deployment stressors have been developed for military families. Most of these programs focus on children (e.g., Lester et al., 2011) and on helping families adjust to changing parenting roles during the various phases of the deployment cycle (Gewirtz, Erbes, Polusny, \& Forgatch, 2011). The few programs designed for military spouses are aimed at providing psychoeducation on the mental health impact of deployment on service members and their families (Makin-Byrd, Gifford, McCutcheon, \& Glynn, 2011), improving spousal communication (Gottman, Gottman, \& Atkins, 2011; Sautter, Armelie, Glynn, \& Wielt, 2011), and fostering resilience (Gewirtz et al., 2011; Lester et al., 2011). While these programs address important issues related to the deployment cycle, they have not been developed to target clinical depression in military spouses.

In addition to the public health significance of treating depressed military spouses, implications of their treatment may positively affect the whole family. The civilian literature has shown that successful treatment of mothers' depression may also help improve symptoms and functioning in their children (Weissman et al., 2006; Swartz et al., 2008). Given findings that military children are at elevated risk for psychopathology in the context of current operational conditions (Chandra et al., 2010; Chartrand et al., 2008; Flake, Davis, Johnson, \& Middleton, 2009), treating depression in their at-home parents is critical. Additionally, depressed spouses who have been successfully treated may be better equipped to provide a protective home environment for service members during the post-deployment phase, when the latter may be suffering from posttraumatic stress symptoms and other adjustment issues (Verdeli et al., 2011).

\section{Rationale for Selecting IPT for Depressed Spouses of Military Service Members}

Empirically-supported treatments (ESTs) adapted to the military context and tested for acceptability of delivery are needed to treat depression in military spouses. Among these treatments, psychotherapy options should be available to account for individual treatment preferences and potential contraindications to medication. For example, psychotherapy may be preferable for pregnant or nursing mothers, an important consideration given that the majority of military spouses are women of childbearing age (APA, 2007).

Our team from Columbia University and the Naval Medical Center Portsmouth, Virginia (NMCP) has received funding from the Navy Bureau of Medicine and Surgery to adapt, test, and evaluate group Interpersonal Psychotherapy for depressed military spouses (IPT-GMS) at NMCP. IPT is one of the leading ESTs for depression (Weissman, Markowitz, \& Klerman, 2007). Based on discussions among the investigators and NCMP mental health professionals who routinely treat this population, as well as a recent literature review on the psychosocial stressors associated with deployment and the mental health needs of military spouses (Verdeli et al., 2011), IPT was identified as a potentially suitable psychotherapy for their depression.

The structure and versatility of IPT lend themselves well to the military context. The treatment has been successfully adapted for a wide range of cultures and patient populations, taking into account the unique contextual factors and logistical issues present in different settings (Weissman et al., 2007). Moreover, it has been administered effectively in a group format, making it cost-effective and potentially sustainable in military clinics 
struggling to meet high treatment demands (Verdeli et al., 2003, 2008). Among military spouses, who share many common life events and stressors, the group format may confer a particular therapeutic benefit. IPT is manualized, promoting ease of training and dissemination. Clinicians from different mental health backgrounds (e.g., social workers, psychologists, and psychiatrists) as well as non-mental health workers (e.g., registered nurses) have shown high levels of treatment adherence and competence, and the treatment has been delivered effectively in community settings. As such, IPT could potentially be disseminated through the variety of different care pathways provided in the military, meeting the needs of spouses with varying circumstances and access to different health services.

Furthermore, the IPT conceptualization of depression provides a good fit with the types of stressors to which military spouses may be exposed before, during, and after deployment. The fundamental principle of IPT is that, regardless of the causes of depression, a given episode is triggered by disturbances in significant interpersonal relationships and social roles (Weissman et al., 2007). In IPT, depressogenic triggers are clustered into four problem areas which form the treatment focus: grief (following the death of a significant other), interpersonal disputes (open or covert disagreements with loved ones or others in the patient's community), role transitions (positive or negative changes in life circumstances), and interpersonal deficits (social difficulties due to significant difficulties in starting and/or sustaining relationships). In civilian populations where depressive episodes appear to have been triggered in response to life stressors (e.g., HIV-positive depressed patients), IPT has shown an advantage over other ESTs, such as Cognitive Behavioral Therapy (Markowitz et al., 1998; Parker, Parker, Brotchie, \& Stuart, 2006). The original four IPT problem areas (Weissman et al., 2007) have been applied to the military context as follows:

\subsection{Grief}

Although grief is a salient issue for depressed spouses who have lost a husband or wife in combat duty, in the group adaption of IPT described below, widowed spouses will be referred to other specialized mental health services already in place. Where grief caused by the loss of other loved ones is a trigger of depression, it will be discussed in the groups. Grieving participants are helped to mourn by reconstructing the relationship with the deceased and recalling their thoughts and feelings about events before, during, and after the death. They are also assisted in the strengthening of existing ties and the formation of new ones, and encouraged to pursue life interests.

\subsection{Interpersonal Disputes}

During deployment, communication between the spouse and service member is one of the greatest challenges (APA, 2007). Although web communication helps spouses connect with loved ones abroad, it may exacerbate safety concerns during unanticipated breaks in communication (National Military Family Association, 2005) or spur feelings of jealousy and suspicions of infidelity (Pincus, House, Christensen, \& Adler, 2005). During the post-deployment period, when both the depressed spouse and service member may struggle to adjust, promoting effective interpersonal communication is vital in resolving disputes and alleviating the spouse's symptoms. Moreover, given that substance use, anger, and other sequelae of posttraumatic stress are common in returning service members, and risk factors for domestic abuse (McCarroll et al., 2010), providing spouses with interpersonal tools to manage arguments may help protect their safety and that of their children. When disputes are the problem area, the IPT therapist helps participants understand and modify discordant expectations about the relationship with the conflicting party and communication patterns that impede resolution of the dispute.

\subsection{Role Transitions}

In the military context, IPT may help depressed spouses navigate the multiple role changes which occur through the various stages of deployment: separation, becoming a temporary "single parent" during deployment, reunion with a service member who may be struggling with post-deployment adjustment, and realignment of roles in a family system that has inevitably changed. Spouses can experience role overload as they take on sole responsibility for the home and family during extended deployments (Drummet, Coleman, \& Cable, 2003). This strain may be exacerbated by financial difficulties (Castaneda et al., 2008), moves to a new base (Flake, Davis, Johnson, \& Middleton, 2009), or, for many families of Reservists and National Guard members, limited access to military-based services including health care (APA, 2007). When role transitions are the identified problem area, the IPT therapist mobilizes the group to assist the participant in mourning the old role, identifying the positive and negative aspects of the old and new roles, building skills, and exploring resources to improve adjustment to the new role. Identifying options and people who can support/advocate for the patients is also important for the successful resolution of role transitions. 


\subsection{Interpersonal Deficits/Social Isolation}

Faced with frequent relocations to new bases, absent partners, and great demands on their time as they juggle multiple responsibilities, spouses with more chronic problems of loneliness and social isolation may have limited interaction with loved ones. Their depression may cause them to withdraw further from potential sources of social support. While Family Readiness Groups organized by the military and religious groups exist to offer support for Army spouses and families, there are uneven levels of participation in such services, and families of Reservists appear to be at a disadvantage (Drummet et al., 2003; MacDermid, 2006). With interpersonal deficits, the IPT therapist assists participants in identifying sources of support and developing new social skills and communication patterns. This helps increase participants' involvement with others, thereby reducing social isolation and loneliness. It also enables participants to gain a sense of control and mastery of their social context, lifting the sense of helplessness and hopelessness associated with depression.

\section{Method for Adapting IPT for Depressed Spouses of Military Service Members}

Findings from our recent literature review (Verdeli et al., 2011) and discussions with mental health providers at NCMP suggest that the structure, focus, and content of IPT are relevant to the interpersonal stressors associated with the deployment cycle. However, we need further information about the logistics of treatment delivery within the military to ensure that spouses have access to IPT-GMS. These pragmatic considerations are essential to promote the intervention's long-term effectiveness, dissemination, and sustainability in the community, and thus enhance its public health impact.

With this in mind, the next step in the development of IPT-GMS is to conduct focus groups with depressed military spouses, the NMCP mental health professionals who routinely treat them, and service members themselves. Information from these groups will help us determine issues surrounding access to care (e.g., child care, financial constraints, confidentiality, stigma) and treatment attitudes (e.g., preference for shorter versus longer, and individual versus group interventions). Additionally, data on depressed military spouses' potential points of professional contact $(\mathrm{OB} / \mathrm{GYN}$; primary care physician; etc.) can help increase the rate of case identification. Focus groups can also provide qualitative data about local community infrastructures to design appropriate and meaningful treatment delivery routes, and thus optimize the delivery of the treatment and promote its scalability.

\section{Evaluation of IPT-GMS}

After adapting the treatment, the next step will be to train NMCP clinicians in IPT-GMS and conduct a pilot study of the intervention. This initial study will evaluate: the feasibility of recruiting and retaining depressed spouses in the treatment; treatment acceptability and safety; therapist adherence to manuals; and preliminary evidence for impact on depression and functioning.

NMCP colleagues currently working with depressed spouses have suggested that, due to work and childcare commitments, they may already feel overburdened and therefore more willing to engage in a shorter treatment. To determine whether a shortened form of IPT-GMS is as acceptable as the standard IPT-GMS, we will develop and test an 8-week against the standard 16-week version. Due to the small sample size in this initial study, we anticipate that there will be little statistical power to detect significant differences between the two treatment versions, and establish the impact of IPT-GMS on depression and functioning. However, in order to check that the intervention is safe and tolerable for this population, initial data on changes in symptoms and functioning will be collected. Depression severity will be measured with the Hamilton Rating Scale for Depression (HRSD; Hamilton, 1960), a widely used clinician-administered interview that assesses the presence and severity of 17 symptoms of depression experienced over the past week. Functioning will be measured with the Social Adjustment Scale-Self Report (SAS-SR; Weissman \& Bothwell, 1976), a 23-item scale that assesses functioning in the last two weeks.

However, this initial study will focus on exploratory analyses of treatment acceptability and feasibility. Treatment satisfaction will be assessed via a survey instrument containing both open-ended questions and Likert-style ratings. Additionally, study participants will complete the Credibility/Expectancy Questionnaire (CEQ; Devilly \& Borkovec, 2000), a 6-item scale that assesses perceived usefulness of treatment, believability, and treatment expectancy. Drop-out rates will provide additional information about treatment acceptability and feasibility. Therapist adherence to treatment protocols will also be evaluated, to establish quality of IPT-GMS administration.

In addition, data will be collected on the impact of the intervention on children and service members. The effect of IPT-GMS on children's emotional and behavioral symptoms will be assessed using the Achenbach Child Behavior Checklist (CBCL), a screening measure that consists of 113 items completed by the parents (Achenbach, 1991, 1992). Children's functioning will be assessed using the Social Adjustment Scale-Self Report (SAS-SR; Weissman, Orvaschel, \& Padian, 1980), a 23-item scale that assesses functioning in five domains: school, relations with 
friends, leisure time, romantic relations, and family behavior. Additionally, we will gather preliminary data on the impact of IPT-GMS on spouses' relationships with their service member partners, using the Dyadic Adjustment Scale (DAS). This is a 32-item scale, designed to measure the quality of adjustment in marriage and other dyads (Spanier, 1976).

Based on findings from this initial study, IPT-GMS will be further refined and tested in a larger, multi-site effectiveness study. This will provide more robust evidence for the treatment's effectiveness and its implications for service members and children. It will also give more information about the study's ecological validity and inform its wider dissemination across the community.

\section{IPT-GMS Strategies and Techniques}

Below we describe existing IPT strategies and techniques and, based on information from our initial formative work with NMCP clinicians to adapt the treatment, offer examples of how they might be applied in IPT-GMS:

\subsection{Assigning the "Sick Role"}

One of the tasks during the pre-group, individual sessions is to assign the "sick role." The IPT therapist tells patients that their depression is a treatable illness. Patients are encouraged to suspend major life decisions as much as possible and to reduce expectations for what they hope to achieve until the depressive episode has passed. The goal is to help patients focus their efforts on combating their depression, identify sources of support, limit their engagement in stressful activities, and diminish their sense of guilt and burden.

Patient: I know I should be happy now Jake's back... but I'm just sat at home all the time crying. There is so much to be done, but I can barely get myself out of bed each day.

Therapist: You're going through such a tough time right now. The sadness and lack of energy you've described-along with your difficulty sleeping, lack of appetite, and guilty feelings—-those are all symptoms of depression.

Patient: My mom said this stuff is all in my head. I guess I should remember that my husband spent the last 12 months getting shot at.

Therapist: Depression is a serious medical condition, just as illnesses like pneumonia or diabetes are. Fortunately there are some excellent, evidence-based treatments available for depression, including Interpersonal Psychotherapy. However, it will take some weeks before you feel better and are able to do things the way you used to.

Patient: I guess, but what if I'm just making excuses? Maybe I'm just lazy.

Therapist: A lot of people feel that way when they're depressed. But it's really important to give yourself some time and space to fight your depression, and to try not to take on commitments that are going to make you feel even more overwhelmed.

Patient: But...my review is coming up at work. And the kids will be off school in a couple of weeks, I promised I'd take them down to Florida to see my parents.

Therapist: That is a lot to deal with. Is there anyone who could help you with any of this-someone you feel particularly close to who could help you through this difficult time?

\subsection{Linking Mood to the Interpersonal Event}

This core IPT technique is emphasized throughout treatment and used to help group members understand the relationship between their mood and the triggering interpersonal event. Group members are encouraged to help each other clarify which interactions worsen their mood and which improve it.

Crystal: I've been feeling really down this week.

Therapist: What happened?

Crystal: I got this weird email from Matt. He was talking about a few days he had off on leave, and what a good time he had with the guys.

Therapist: And how did you feel after reading Matt's message?

Crystal: Lonely, I guess... I mean, Matt almost sounded happy. You know, things haven't been easy on my own here. But, I feel terrible for thinking that, I mean he's the one in Afghanistan.

Therapist: It sounds like reading that email brought your mood right down, Crystal. We will talk more about this later. You and other members of the group have mentioned how hard emailing back and forth during deployments 
can be, so we'll work on some strategies for managing that type of difficult communication. How was your week, Emily?

Emily: Okay, I guess. I mean, when I left here last week I was fine, and I did pretty well up until Saturday. But then I opened my credit card bill, which stressed me out. And then, that afternoon, the kids were acting up and I just lost it with them. I've been a mess ever since.

\subsection{Conducting Communication Analysis}

This technique involves detailed analysis of a difficult interpersonal interaction reported by a group member, to understand when, how, and why the communication broke down. Often, the IPT therapist uses a video camera metaphor to convey the idea of reviewing the interaction "frame by frame." The goal of communication analysis is to help members clarify what information they wished to convey, understand what prevented effective expression, and take ownership of the message they are communicating.

Therapist: Jenn, you just told us how your argument with Keith really got you down for the rest of the week, and I can see in your face how low you're still feeling now. To understand all this better, it's important to go back and look at exactly what happened during the argument, frame-by-frame. If it was taped on a video camera, what would we see?

Jenn: It was Friday night and I was home with the kids... Keith was at the bar, again. John wouldn't sleep, I guess he's teething right now.... and the house was looking like a total dump, with stuff everywhere.... and then Keith came in totally wasted.

Therapist: And what did you say?

Jenn: That he might as well be back in Iraq, for all the good it was doing having him home. And then Keith said that at least over there he didn't have me on his back all the time. I was so mad.

Therapist: Can you remember what you said after that?

Jenn: I can't remember exactly. Something like, "You think it's so darn easy looking after the kids on my own, working this crappy job to try and make ends meet, while you're off playing the big hero."

Emily: I think I said something similar to Eric! Sometimes they don't get how tough it is on us, too.

Jenn: Yeah, they really don't. And then Keith raised his hand to slap me, but John started crying so he just turned around and stormed out of the house.

Therapist: How did you feel when he left?

\subsection{Generating Options}

IPT therapists encourage the group to work together to generate solutions to individual members' interpersonal problems. Members are encouraged to conduct a "decision analysis," in which they weigh up the pros and cons of the different options available and choose between them. Members who are feeling particularly helpless are encouraged to identify others who can advocate for them until they are feeling more empowered.

\subsection{Role-playing}

Once a course of action has been selected for one of the group members, the IPT therapist facilitates a role-play with someone else from the group to rehearse the conversation required to achieve his or her aim. They may alternate roles to help members see how their message might be perceived by the different parties involved. The therapist also teaches skills to improve the effectiveness of the communication. These include clarifying the interpersonal message the person wants to communicate, choosing an appropriate setting for the discussion (a time and location where involved parties will be willing to listen to each other), staying on topic and addressing the issue at hand, listening actively to the other person, and communicating effectively (verbally and non-verbally).

\subsection{Assigning Homework}

Homework puts into action the decisions made in sessions, using the interpersonal skills practiced in role-plays. During each session, the group evaluates how the members' planned interactions went, and any difficulties that emerged are addressed.

\section{Conclusion}

Our team is in the process of adapting and testing IPT-GMS, a group interpersonal psychotherapy for depressed military spouses. The IPT focus on interpersonal life stressors as triggers of depression appears particularly relevant to the needs of depressed spouses struggling to cope with the demands of the deployment cycle. The treatment's time-limited, flexible structure may enhance its acceptability to patients and clinicians alike. 
This research has the potential to produce a treatment modality that can be readily adopted by military mental health professionals and may significantly improve the psychological health of spouses of deployed service members and their families. To date, there is no published study of treatments addressing the unique needs of depressed military spouses, and there is only minimal data to inform best practice guidelines for psychological health in military families in need of psychological support during the deployment cycle. The current study aims to help address this imbalance.

\section{References}

Achenbach, T. M., \& Rescorla, L. A. (2001). Manual for the ASEBA School-Age Forms and Profiles. Burlington, VT: University of Vermont, Research Center for Children, Youth, and Families.

Achenbach, T. M., \& Rescorla, L. A. (2000). Manual for the ASEBA Preschool forms and Profiles. Burlington, VT: University of Vermont Department of Psychiatry.

American Psychological Association Presidential Task Force on Military Deployment Services for Youth, Families, and Service Members. (2007). The psychological needs of U.S. military service members and their families: A preliminary report. Washington, DC: American Psychological Association.

Castaneda, L. W., Harrell, M. C., Varda, D. M., Hall, K.C., Beckett, M. K., \& Stern, S. (2008). Deployment experiences of Guard and Reserve families. Santa Monica, CA: RAND.

Castro, A. B. Adler, \& T. W. Britt (Eds.), Military life: The psychology of serving in peace and combat (vol. 3): The military family (pp. 13-38). Westport, CT: Praeger Security International.

Chandra, A., Lara-Cinisomo, S., Jaycox, L. H., Tanielian, T., Bums, R. M., Ruder, T., \& Han, B. (2010). Children on the homefront: The experience of children from military families. Pediatrics, 125, 16-25. http://dx.doi.org/10.1542/peds.2009-1180

Chartrand, M., Frank, D., White, L., \& Shope, T. (2008). Effects of parents' wartime deployment on the behavior of young children in military families. Archives of Pediatric \& Adolescent Medicine, 162, 1009-1014. http://dx.doi.org/10.1001/archpedi.162.11.1009

Cozza, S. J., Chun, R. S., \& Polo, J. A. (2005). Military families and children during operation Iraqi freedom. The Psychiatric Quarterly, 76, 371-378. http://dx.doi.org/10.1007/s11126-005-4973-y

Deputy Under Secretary of Defense. (2009). Demographics profile of the military community. Washington, DC: Office of the Deputy Under Secretary of Defense.

Devilly, G. J., \& Borkovec, T. D. (2000). Psychometric properties of the credibility/expectancy questionnaire. Journal of Behavior Therapy and Experimental Psychiatry, 31, 73-86. http://dx.doi.org/10.1016/S0005-7916(00)00012-4

Drummet, A., Coleman, M., \& Cable, S. (2003). Military families under stress: Implications for family life education. Family Relations, 52, 279-282. http://dx.doi.org/10.1111/j.1741-3729.2003.00279.x

Eaton, K. M., Hoge, C. W., Messer, S. C., Whitt, A. A., Cabrera, O. A., McGurk, D., Cox, A., \& Castro, C. A. (2008). Prevalence of mental health problems, treatment need, and barriers to care among primary care-seeking spouses of military service members involved in Iraq and Afghanistan deployments. Military Medicine, 173, 1051-1056.

Flake, E. M., Davis, B. E., Johnson, P. L., \& Middleton, L. S. (2009). The psychosocial effects of deployment on military children. Journal of Developmental \& Behavioral Pediatrics, 30, 271-278. http://dx.doi.org/10.1097/DBP.0b013e3181aac6e4

Gewirtz, A. H., Erbes, C. R., Polusny, M. A., \& Forgatch, M. S. (2011). Helping military families through the deployment process: Strategies to support parenting. Professional Psychology: Research and Practice, 42, 56-62. http://dx.doi.org/10.1037/a0022345

Gorman, L. A., Blow, A. J., Ames, B. D., \& Reed, P. L. (2011). National Guard families after combat: mental health, use of mental health services, and perceived treatment barriers. Psychiatric Services, 62, 28-34. http://dx.doi.org/10.1176/appi.ps.62.1.28

Gottman, J. M., Gottman, J. S., \& Atkins, C. L. (2011). The Comprehensive Soldier Fitness program: Family skills component. The American Psychologist, 66, 52-57. http://dx.doi.org/10.1037/a0021706

Hamilton, M. (1960). A rating scale for depression. Journal of Neurology, Neurosurgery \& Psychiatry, 23, 56-62. http://dx.doi.org/10.1136/jnnp.23.1.56 
Kessler, R. C., Berglund, P., Demler, O., Jin, R., Koretz, D., Merikangas, K. R., \& Wang, P. S. (2003). The epidemiology of major depressive disorder: Results from the national Comorbidity Survey Replication (NCS-R). JAMA, 289, 3095-3105. http://dx.doi.org/10.1001/jama.289.23.3095

Kessler, R. C., McGonagle, K. A., Zhao, S., Nelson, C. B., Hughes, M., Eshleman, S., Wittchen, H. U., \& Kendler, K. S. (1994). Lifetime and 12-month prevalence of DSM-III-R psychiatric disorders in the United States. Results from the National Comorbidity Survey. Archives of General Psychiatry, 51, 8-19. http://dx.doi.org/10.1001/archpsyc.1994.03950010008002

Lester, P., Leskin, G., Woodward, K., Saltzman, W., Nash, W., Mogil, C., Paley, B., \& Beardslee W. R. (2011). Wartime deployment and military children: Applying prevention science to enhance family resilience. In S. MacDermid Wadsworth \& D. Riggs (Eds.), Risk and resilience in U.S. military families (pp. 149-173). New York, NY: Springer Science and Business Media. http://dx.doi.org/10.1007/978-1-4419-7064-0_8

Lester, P., Peterson, K., Reeves, J., Knauss, L., Glover, D., Mogil, C., \& Beardslee, W. (2010). The long war and parental combat deployment: Effects on military children and at-home spouses. Journal of the American Academy of Child \& Adolescent Psychiatry, 49, 310-320. http://dx.doi.org/10.1097/00004583-201004000-00006

MacDermid, S. M. (2006). Multiple transitions of deployment and reunion for military families. Purdue University. [Online] Available: http://www.cfs.purdue.edu/mfri/pages/research/DeployReunion.pdf (May 2, 2011)

Makin-Byrd, K. Gifford, E., McCutcheon, S., \& Glynn, S. (2011). Family and couples treatment for newly returning veterans. Professional Psychology: Research and Practice, 42, 47-55. http://dx.doi.org/10.1037/a0022292

Mansfield, A. J., Kaufman, J. S., Marshall, S. W., Gaynes, B. N., Morrissey, J. P., \& Engel, C. (2010). Deployment and the use of mental health services among U.S. Army wives. The New England Journal of Medicine, 362, 101-109. http://dx.doi.org/10.1056/NEJMoa0900177

Markowitz, J. C., Kocsis, J. H., Fishman, B., Spielman, L. A., Jacobsberg, L. B., Frances, A. J., Klerman, G. L., \& Perry, S. W. (1998). Treatment of Depressive Symptoms in Human Immunodeficiency Virus-Positive Patients. Archives of General Psychiatry, 55, 452-457. http://dx.doi.org/10.1001/archpsyc.55.5.452

McCarroll, J. E., Ursano, R. J., Liu, X., Thayer, L. E., Newby, J. H., Norwood, A. E., \& Fullerton, C. S. (2010). Deployment and the probability of spousal aggression by U.S. Army soldiers. Military Medicine, 175, 352-356.

National Military Family Association. (2004). Serving the home front: An analysis of military family support from September 11, 2001 through March 31, 2004. Alexandria, VA: National Military Family Association.

National Military Family Association. (2005). Report on the Cycles of Deployment: An Analysis of Survey Responses from April through September, 2005. Alexandria, VA: National Military Family Association.

Parker, G., Parker, I., Brotchie, H., \& Stuart, S. (2006). Interpersonal psychotherapy for depression? The need to define its ecological niche. Journal of Affective Disorders, 95, 1-11. http://dx.doi.org/10.1016/j.jad.2006.03.019

Pincus, S.H., House, R., Christensen, J., \& Adler, L.E. (2005). The emotional cycle of deployment: a military family perspective. [Online] Available: http:/www.hooah4health.com/deployment/familymatters/emotionalcycle.htm (January 22, 2007)

Sautter, Frederic J., Armelie, A. P., Glynn, S. M., \& Wielt, D. B. (2011). The development of a couple-based treatment for PTSD in returning veterans. Professional Psychology: Research and Practice, 42, 63-69. http://dx.doi.org/10.1037/a0022323

Sheppard, S. C., Malatras, J. W., \& Israel, A. C. (2010). The impact of deployment on U.S. military families. American Psychologist, 65, 599-609. http://dx.doi.org/10.1037/a0020332

Spanier, G. B. (1976). Measuring Dyadic Adjustment: New Scales for Assessing the Quality of Marriage and Similar Dyads. Journal of Marriage and the Family, 38, 15-28. http://dx.doi.org/10.2307/350547

Swartz, H. A., Frank, E., Zuckoff, A., Cyranowski, J. M., Houck, P. R., Cheng, Y., \& Shear, K. M. (2008). Brief Interpersonal Psychotherapy for depressed mothers whose children are receiving psychiatric treatment. American Journal of Psychiatry, 165, 1155-1162. http://dx.doi.org/10.1176/appi.ajp.2008.07081339

Verdeli, H., Baily, C., Vousoura, E., Belser, A., Singla, D., \& Manos, G. (2011). The case for treating depression in military spouses. Journal of Family Psychology, 25, 488-496. http://dx.doi.org/10.1037/a0024525

Verdeli, H., Clougherty, K., Bolton, P., Speelman, L., Lincoln, N., Bass, J., +Neugebauer, R., \& Weissman, M. M. 
(2003). Adapting group interpersonal psychotherapy for a developing country: experience in rural Uganda. World Psychiatry, 2(2), 114-120.

Verdeli, H., Clougherty, K., Onyango, G., Lewandowski, E., Speelman, L., Betancourt, T. S., \& Neugebauer, R., Stein, T.R., Bolton, P. (2008). Group Interpersonal Psychotherapy for depressed youth in IDP camps in Northern Uganda: adaptation and training. Child and Adolescent Psychiatric Clinics of North America, 17(3), 605-624, ix. http://dx.doi.org/ 10.1016/j.chc.2008.03.002

Weissman, M. M., \& Bothwell, S. (1976). Assessment of social adjustment by patient self-report. Archives of General Psychiatry, 33, 1111-1115. http://dx.doi.org/10.1001/archpsyc.1976.01770090101010

Weissman, M. M., Markowitz, J. C., \& Klerman, G. L. (2007). Clinician's Quick Guide to Interpersonal Psychotherapy. New York, NY: Oxford University Press.

Weissman, M. M., Orvaschel, H., \& Padian, N. (1980). Children's symptom and social functioning self-report scales. Comparison of mothers' and children's reports. The Journal of Nervous and Mental Disease, 168(12), 736-740. http://dx.doi.org/10.1097/00005053-198012000-00005

Weissman, M. M., Pilowsky, D. J., Wickramaratne, P. J., Talati, A., Wisniewski, S. R., Fava, M., \& Rush, A. J. (2006). Remissions in Maternal Depression and Child Psychopathology. Journal of the American Medical Association, 295, 1389 -1398. http://dx.doi.org/10.1001/jama.295.12.1

Wiens, T.W., \& Boss, P. (2006). Maintaining family resiliency before, during, and after military separation. In C. A. Castro, A. B. Adler, \& C. A. Britt (Eds.), Military life: The psychology of serving in peace and combat (Vol. 3, pp. 13-38). Bridgeport, CT: Praeger Security International. 